\title{
New strategies focused on endoplasmic reticulum for treatment of human diseases
}

\author{
Horakova Lubica* \\ Institute of Experimental Pharmacology and Toxicology, Slovak Academy of Sciences, Slovakia
}

Accumulating evidence suggests that many serious human diseases related to oxidative stress (diabetes, cancer, heart and neurodegenerative diseases) are associated with stress of endoplasmic reticulum (ER) and are called also ER diseases. Proper function of ER requires a steep calcium gradient. In the extracellular space, the $\mathrm{Ca}^{2+}$ level reaches $1 \mathrm{mM}$, whereas in the intracellular space it is maintained around the value of $100 \mathrm{nM}$ [1]. Without this gradient cells undergo ER stress and cell death. ER is a network of membranes with mutual functions, focused on production, processing, and transport of proteins and lipids as well as on maintaining the calcium storage. Moreover, ER possesses regulatory abilities like redox controlling, cell signaling and cell death. To summarize these properties, ER is deciding about survival or death of cells.

A novel therapeutic approach is to develop drugs targeted to ER dysfunction. ER homeostasis, i.e. normal function of ER, is maintained by calcium and redox homeostasis as well as by correct protein folding. Sarco/endoplasmic reticulum $\mathrm{Ca}^{2+}$-ATPase (SERCA) is an enzyme playing a crucial role in maintaining a physiological level of $\mathrm{Ca}^{2+}$ inside the cells.

In addition to the SERCA, the calcium channels such as ryanodine receptors and inositol trisphospate receptors are another possibilities as targets to influence ER calcium homeostasis [2].

Both physiological and pathophysiological levels of ROS/RNS regulate cell functions by modifications of SERCA. This regulation of cell function may suggest new strategies to prevent vascular diseases and development of cancer. Flavonoids and other small molecules are able to elevate cytosolic $\left(\mathrm{Ca}^{2+}\right)$ at least partially via SERCA and thus may be a useful tool for preventing cancer development. On the other hand, some flavonoids significantly increased cell viability and protected against cardiomyocyte apoptosis via preservation of SERCA function, which can be a novel strategy against cardiovascular diseases associated with oxidative stress $[3,4]$. ER plays also a more important role in type 2 diabetes and its complications than believed previously. Pancreatic beta cells and neurons are particularly sensitive to ER dysfunction associated with impairment of calcium homeostasis.

Recently we found a correlation between decrease of SERCA activity induced by the quercetin derivative chloronaphtochinonequercetin and its anticancer effect in colorectal cell lines HCT-116 and HT-29 [5]. Relationship between SERCA activity decrease and apoptosis was indicated also with respect to curcumin [6]. On the other hand, tetra(trimethylgalloyl)oxyferuloylquercetin, a derivative which increased SERCA activity, showed protective effect on pancreatic beta cells [7].

\section{Acknowledgements}

This work was supported by APVV-15-0455.

\section{References}

1. Rizzuto R, Marchi S, Bonora M, Aguiari P, Bononi A, et al. (2009) $\mathrm{Ca}(2+)$ transfer from the ER to mitochondria: when, how and why. BiochimBiophysActa 1787: 1342-1351. [Crossref]

2. Urano F (2016) Wolfram Syndrome: Diagnosis, Management, and Treatment. CurrDiab Rep 16: 6. [Crossref]

3. Horakova L (2011) Flavonoids in prevention of diseases with respect to modulation of Ca-pump function. InterdiscipToxicol4: 114-124. [Crossref]

4. Horakova L, Strosova M, Spickett CM, Blaskovic D (2013) Impairment of calcium ATPases by high glucose and potential pharmacological protection. Free Radic Res 47: 81-92. [Crossref]

5. Zizkova P, Stefek M, Rackova L, Soltesova-Prnova M, Horakova L (2017) Novel quercetin derivatives: From redox properties to promising treatment of oxidative stress related diseases. Chem-biol interactions 265: 36-46.

6. Bilmen JG, Khan SZ, Javed MH, Michelangeli F (2001) Inhibition of the SERCA $\mathrm{Ca} 2+$ pumps by curcumin. Curcumin putatively stabilizes the interaction between the nucleotide-binding and phosphorylation domains in the absence of ATP. Eur J Biochem 268: 6318-6327. [Crossref]

7. Heger V. Zizkova P. Viskupicova J. (2017) Tetra(trimethylgalloyl)oxyferuloylquercetin protective effect on beta cell viability decrease induced by methylglyoxal in the pancreatic INS-1E cell line. Eur Pharm J. [In press].
Copyright: (C2017 Lubica H. This is an open-access article distributed under the terms of the Creative Commons Attribution License, which permits unrestricted use, distribution, and reproduction in any medium, provided the original author and source are credited.
Correspondence to: Horakova Lubica, Institute of Experimental Pharmacology and Toxicology, Slovak academy of Sciences, Bratislava, Slovakia, E-mail: lubica. horakova@savba.sk

Received: June 03, 2017; Accepted: June 23, 2017; Published: June 26, 2017 